\title{
EVOCACIONES CERVANTINAS EN TIRSO ${ }^{1}$
}

\author{
Evocations of Cervantes in Tirso
}

Blanca Oteiza*

Resumen

Este trabajo trata de las relaciones, inexistentes, probables o seguras, entre ambos escritores teniendo en cuenta cuatro aspectos: si se conocieron; la presencia de Tirso en Cervantes, la influencia de Cervantes en Tirso y la evocación cervantina en la obra del Mercedario.

Palabras clave: Tirso, Cervantes, Relaciones, Influencias.

\section{Abstract}

This article analyses the non-existent, probable or concrete relationships between both writers: Cervantes and Tirso de Molina. The analysis focuses on four aspects: the probability that both of them met and knew each other, the presence of Tirso in the works by Cervantes, the influence of Cervantes in the plays of Tirso and Cervantes evocation in the works of the friar.

Key words: Tirso, Cervantes, Relationship, Influence.

Las relaciones, inexistentes, probables o seguras, entre ambos escritores giran en torno a cuatro aspectos, que atenderé por este orden, con el objetivo de ofrecer un panorama actualizado y comentado respecto del tema: el de sus relaciones, el de la presencia de Tirso en Cervantes, el de la influencia de Cervantes en Tirso y el de la evocación cervantina en la obra del Mercedario.

\section{¿SE CONOCIERON TIRSO Y CERVANTES?}

Cuando se publica la primera parte del Quijote en 1605 (Madrid, Juan de la Cuesta) Cervantes vive en Valladolid, donde permanece quizá hasta marzo de 1606, cuando se traslada a Madrid, y Tirso en Toledo, donde ha empezado su carrera de dramaturgo, pues en 1606 ya hay constancia de su producción teatral. Y cuando se publican las Novelas ejemplares (1613), el Viaje del Parnaso (1614), la segunda parte del Quijote (1615) y póstumamente el Persiles (1617), Cervantes continúa residiendo en Madrid y Tirso, ya autor de éxito, sigue en Toledo con algunas ausencias hasta 1616, año en que se embarca para Santo Domingo, de donde regresará en 1618, por lo que no está en España en el momento de publicarse el Persiles, que leerá sin embargo más adelante ${ }^{2}$.

\footnotetext{
${ }^{1}$ Este trabajo se enmarca en el Proyecto Edición crítica del teatro completo de Tirso. Cuarta fase, subvencionado por el Ministerio de Economía y Competitividad de España, referencia FFI2013-48549-P.

${ }^{2}$ Ver respectivamente García López (187, 198) y Vázquez (Tabula, 9-47).
} 


\section{Blanca Oteiza}

No consta que Cervantes y Tirso se conocieran personalmente ${ }^{3}$, pero sí que el Mercedario está al corriente de la obra de Cervantes como evidencia en su teatro y prosa, y que Cervantes debió de estar enterado de la de Tirso, es decir, su teatro representado hasta 1616 (no así su prosa que redacta a partir de 1621, Cigarrales de Toledo, cuando Cervantes está muerto), porque aunque no es fácil datar sus comedias de estos años toledanos, de 1609 a 1615 ya había escrito comedias de éxito como $L a$ villana de la Sagra (1609), Mari Hernández, la gallega (1610-1611), Cómo han de ser los amigos (1612), La santa Juana (1613-1615), Don Gil de las calzas verdes (1615), Marta la piadosa $(1614-1615)^{4} \ldots$

$\mathrm{Y}$ así como contamos con referencias de Tirso a Cervantes de admiración, reconocimiento y distancia, no disponemos de menciones expresas de Cervantes a Tirso. Esta ausencia ha llamado la atención de la crítica desde el siglo XIX, que ha planteado propuestas con más imaginación que fortuna acerca de esta relación en la que suele incluirse también a Lope ${ }^{5}$, como la de Abrams que defendía en los años sesenta que Quijote y Sancho son representaciones satíricas de Lope y Tirso (1968a y 1969). De manera que así como consta que las relaciones entre Lope y Cervantes fueron de admiración y rivalidad recíproca ${ }^{6}$ no podemos certificar lo mismo entre Cervantes y Tirso, excepto constatar que el Mercedario conoce, alude y habla explícitamente de la obra de Cervantes y que este silencia la de Tirso.

\section{PRESENCIA DE TIRSO EN CERVANTES}

A pesar de ello la crítica no solo ha querido ver también en la obra de Cervantes referencias al Mercedario, concretamente en Viaje del Parnaso, sino incluso conectar muy directamente ambos autores, proponiendo a Tirso como el autor del Quijote de Avellaneda.

\footnotetext{
${ }^{3}$ Ambos se llevan 32 años y mueren prácticamente a la misma edad: Cervantes (Alcalá de Henares, 1547Madrid, 1616); Gabriel Téllez (Madrid, 1579-Almazán (Soria), 1648). Sin embargo Vázquez cree que Cervantes no podía ignorar a Tirso porque en 1609 enterró en la iglesia madrileña de San Sebastián a su hermana Andrea, que vivía, como él, en la calle de la Magdalena, cerca del convento de la Merced, donde era monja una hermana de Tirso, Catalina Téllez (1303-1304).

${ }^{4}$ Ver las cronologías de Palomo (17-27), que reconoce la dificultad de datar el teatro del Mercedario (16, nota 2), y de Vázquez (Tabula, 16-17), así como las introducciones de las comedias de Tirso, La villana de la Sagra, Mari Hernández, la gallega, Cómo han de ser los amigos y Don Gil de las calzas verdes y Marta la piadosa.

${ }^{5}$ Ver las propuestas de Kennedy para las relaciones de Tirso con Cervantes, Hurtado de Mendoza, Vélez de Guevara y Lope, y la de Florit para la de Tirso y Lope.

${ }^{6}$ Recuérdese que se atribuye a Lope una carta fechada el 14-8-1604 en la que dice que de los poetas "ninguno hay tan malo como Cervantes ni tan necio que alabe a don Quijote" (Sliwa, I, 111-112). Esto supone que Lope conocía el Quijote antes de su publicación (el privilegio real está fechado en Valladolid el 26 de septiembre de 1604).
} 
Referencias a Tirso en Viaje del Parnaso

Quizá porque en Viaje del Parnaso Cervantes da cabida a poetas de importancia menor, pero no incluye a Tirso, se ha querido advertir su presencia en dos pasajes con propuestas más o menos razonables.

Así, se ha venido defendiendo con cierta cautela (Asensio) que unos tercetos están referidos a Tirso, en el sintagma "el otro". Es un pasaje en el que Cervantes elogia al también mercedario Remón, amigo de Lope y dramaturgo como Tirso con el que tuvo sus más y sus menos ${ }^{7}$. Es decir Cervantes conoce a Remón y al "otro" cuando dice:
Un licenciado de un ingenio inmenso es aquél, $y$, aunque en traje mercenario, como a señor le dan las Musas censo; Ramón se llama, auxilio necesario con que Delio se esfuerza y ve rendidas las obstinadas fuerzas del contrario. El otro, cuyas sienes ves ceñidas con los brazos de Dafne en triunfo honroso, sus glorias tiene en Alcalá esculpidas; en su ilustre teatro vitorioso le nombra el cisne, en canto no funesto, siempre el primero, como a más famoso (IV, vv. 310-321).

La asociación entre los dos mercedarios se justifica por el contexto, pero no tiene consistencia alguna, de hecho el padre Vázquez identifica este "otro"que viene detrás del mercedario Remón, no con Tirso, sino con don Bernardo de Sandoval y Rojas, cardenal-arzobispo de Toledo, que había fundado en Alcalá el convento de Bernardas, es decir, el "monseñor que hace versos" mencionado versos antes (vv. 256 y ss.), razón por la que le llama ahora "el otro", por haber sido ya señalado anteriormente (Vázquez,Tirso,1304).

El otro pasaje corresponde a la Adjunta al Parnaso donde se incluye una mención discordante a Juana Téllez:

Que el más pobre poeta del mundo [...] pueda decir que es enamorado, aunque no lo esté, y poner el nombre a su dama como más le viniere a cuento, ora llamándola Amarili, ora Anarda, ora Clori, ora Filis, ora Fílida, o ya Juana Téllez (318-319),

coincidente curiosamente con el nombre de la madre de Tirso, por lo que Cervantes estaría lanzando un dardo injurioso al Mercedario ${ }^{8}$.

\footnotetext{
${ }^{7}$ Ver Florit (Una comedia, 210, nota 15).

${ }^{8}$ Vázquez, Tirso, 1303.
} 


\section{Blanca Oteiza}

\section{Tirso, autor del Quijote de Avellaneda}

El segundo caso significativo de este empeño en relacionar a Cervantes con Tirso es ni más ni menos el que defiende ser Tirso el autor del Quijote de Avellaneda ${ }^{9}$. Las razones pueden ser tan peregrinas como la de Abrams ${ }^{10}$ que ve en algunos comentarios del prólogo de la Segunda parte "inteligentes" alusiones a Tirso, y lo confirma basándose en que el personaje Pedro Noriz es anagrama que conecta con Tirso. Recordemos que Pedro Noriz es el ficticio nombre del caballero barcelonés, amigo de don Antonio Moreno, el huésped de don Quijote (II, 62), cuya única intervención es hacer una pregunta a la cabeza encantada:

Luego llegó uno de los dos amigos de don Antonio y le preguntó:

— ¿Quién soy yo?

Y fuele respondido:

-Tú lo sabes.

- No te pregunto eso -respondió el caballero-, sino que me digas si me conoces tú.

- Sí conozco -le respondieron-, que eres don Pedro Noriz.

- No quiero saber más, pues esto basta para entender, joh cabeza!, que lo sabes todo.

Es el mercedario Luis Vázquez el que retoma esta hipótesis en 1999, siguiendo a Díaz Solís (1978), y la apoya entre otras razones con unos versos de la comedia $E l$ castigo del penseque, en los que se menciona la novela del Quijote no como "segunda parte" sino "tomo segundo", es decir, como se titula la obra de Avellaneda y de la que Tirso sería el verdadero autor: Segundo tomo del Ingenioso Hidalgo... compuesto por Alonso Fernández de Avellaneda, natural de Tordesillas.

\section{INFLUENCIA DE CERVANTES EN TIRSO}

La influencia de Cervantes en la obra del Mercedario es innegable en temas, motivos, episodios (de hecho Blanca de los Ríos llegó a hablar del periodo cervántico de Tirso), pero no siempre se ha justificado convincentemente. Así la comedia tirsiana El melancólico y el auto sacramental No le arriendo la ganancia se han conectado con la novela ejemplar El licenciado Vidriera (Blanca de los Ríos, 1941 y Jones, 1973), si bien De los Ríos interpreta sin mucho sentido la novela de Cervantes como un ataque al Mercedario, y considera que el auto sacramental tirsiano se transmuta en la novela ejemplar El licenciado Vidriera; García Martín (1978) enlaza las comedias Palabras y plumas y Quien da luego da dos veces, esta de autoría no confirmada, con las novelas ejemplares El amante liberal y La señora Cornelia, deuda que entiende como una

\footnotetext{
${ }^{9}$ Ver los candidatos sugeridos para su autoría en la introducción a la edición de Fernández de Avellaneda, Segundo tomo de El ingenioso hidalgo don Quijote de la Mancha (2014: XXIX-XXXII); añádanse Vázquez, (Tirso), y para la participación de Lope y Tirso en su redacción, en Madrigal.

${ }^{10}$ Abrams (Pedro Noriz).
} 
especie de desafio literario a Cervantes por parte de Tirso ${ }^{11}$. Más recientemente Rosa Navarro, al estudiar Don Gil de las calzas verdes a la luz de la obra de Cervantes, hace, entre otras cosas, una original propuesta, la de que en las calzas verdes hay un eco de la segunda parte del Quijote donde aparece el Caballero del Verde Gabán, razonando la influencia por las fechas: Tirso pudo haber leído u hojeado manuscritos tanto del volumen de Ocho comedias y ocho entremeses nuevos, como de la segunda parte del Quijote publicados unos meses después, lo que justificaría el color verde de las calzas de don Gil. Y últimamente Ana Suárez ha establecido con autoridad las relaciones entre El celoso extremeño cervantino y la comedia tirsiana El celoso prudente y su novela corta Los tres maridos burlados.

Otras situaciones certifican esta influencia de Cervantes en Tirso, en episodios como el de Feliciana de la Voz en el Persiles (III, 2-5) relacionado con el del nacimiento de Francisco Pizarro en la comedia tirsiana Todo es dar en una cosa de la Trilogía de los Pizarro (Osuna, 1974) o el del lamento de Sancho por la pérdida de su asno (Quijote, I, 1348-1349), que Tirso remedará reiteradamente en las comedias $L a$ mujer que manda en casa, La mejor espigadera, El cobarde más valiente, Antona García y El laberinto de Creta ${ }^{12}$.

\section{EVOCACIONES CERVANTINAS EN TIRSO}

Apenas se registran en Tirso unas ocho menciones directas de Cervantes y su obra, seis en su teatro y dos en sus misceláneas Cigarrales de Toledo y Deleitar aprovechando (escritas cuando Cervantes ya ha muerto), pero están bien definidas en su contexto y función: en el teatro se insertan en microtextos con carácter retórico y en la prosa como medio de elogio y distancia de la novela cervantina.

Las referencias cervantinas en su teatro sin excepción de género giran en torno a situaciones y temas claves del Quijote: el viaje incierto, la aventura, el mundo encantado y la locura.

Son viajes que inician o son consecuencia de las peripecias del personaje, generalmente tras situaciones mal dadas, por las que el caballero y su criado abandonan sus lugares y es aquí donde se establece la correspondencia con la pareja QuijoteSancho, que funciona a modo de la pintura de un emblema.

\section{No le arriendo la ganancia}

Así en el auto No le arriendo la ganancia, donde hay evidentes referencias al Quijote y a la novela ejemplar El licenciado Vidriera, Honor declara sus deseos de abandonar la aldea para irse a la corte. Y en el adiós a la aldea se inserta la referencia

\footnotetext{
${ }^{11}$ Insiste en esta deuda Vaiopoulos.

${ }^{12}$ Ver asimismo las propuestas de Close y Friedman. Jurado establece otras deudas tirsianas con Cervantes sin justificación alguna.
} 


\title{
Blanca Oteiza
}

cervantina, desde una perspectiva paródica y en boca de Recelo, el gracioso rústico, remedando al caballero andante y su escudero:

\author{
Pues vas a la corte, \\ llévame contigo, \\ y de un don Quijote \\ seré un Sancho Panza \\ que andaré al galope (vv. 603-607).
}

Pero Honor convertido en valido de Poder terminará por enloquecer y creerse de vidrio, regresando al fin a la aldea tras arrepentirse de sus fantasías vanas, en un trayecto de aldea a corte y de esta a la aldea, en el que la evocación cervantina es evidente.

\section{Tanto es lo de más como lo de menos}

Una situación semejante en la comedia bíblica Tanto es lo de más como lo de menos permite otra alusión a Quijote y Sancho: el caballero Liberio, rechazado por su dama, y su criado Gulín se marchan de la ciudad y en la despedida el criado rememora la salida de don Quijote y Sancho:

$$
\begin{aligned}
& \text { Yo, lacayo Gandalín, } \\
& \text { y el primero que anda a mula, } \\
& \text { trompetero de la gula, } \\
& \text { que por eso soy Gulín, } \\
& \text { ya en jumento, ya en rocín, } \\
& \text { ya de portante, ya al trote, } \\
& \text { comiendo a pasto o a escote, } \\
& \text { daré a venteros venganza, } \\
& \text { no me llamen Sancho Panza, } \\
& \text { que se enoja don Quijote (992). }
\end{aligned}
$$

\section{El castigo del penseque}

Y en la comedia palatina El castigo del penseque son las sorprendentes aventuras del protagonista las que permiten la mención cervantina, que aquí no se limita solo a Quijote y Sancho, y sus cabalgaduras, sino expresamente al autor y su obra: el español don Rodrigo llega a Flandes con su criado Chinchilla en busca de fortuna y es confundido por la familia y la ciudad con Otón, un rico flamenco. La asombrosa situación causa perplejidad en el español y el criado que ofrece al instante la correspondencia en términos de analogía y ponderación cervantinas:

$$
\begin{array}{ll}
\text { D. Rodrigo } & \text { ¿Hay sucesos semejantes? } \\
\text { Chinchilla } & \text { Cuando lo llegue a saber } \\
& \text { Madrid, los ha de poner } \\
& \text { en sus novelas Cervantes. } \\
& \text { Aunque en el tomo segundo }
\end{array}
$$


de su manchego Quijote

no estarán mal, como al trote

los lleven por ese mundo

las ancas de Rocinante

o el burro de Sancho Panza (686).

\section{Amar por señas}

El mundo encantado de la novela de caballerías favorece también la referencia cervantina en la comedia palatina, Amar por señas, en la que el caballero don Gabriel y su criado Montoya son protagonistas de desconcertantes y misteriosas aventuras en un espacio encantado que evocará jocosamente, como es de esperar, los mundos de la caballería, con la mención de motivos y situaciones tipificados y la enumeración de personajes famosos contenidos en el Quijote: Amadís, Esplandián, Belianís, Oriana, Lindabridis... pero también Dulcinea, Sancho Panza, Micomicona... Y es que Montoya el criado no es idiota, sabe leer y conoce bien las novelas de caballerías y está a la última de las novedades quijotescas como demuestra cuando se dirige a la dama Armesinda, enamorada de su amo equiparándola a Dulcinea: "¿Sois la infanta / Lindabrides a lo Febo [...] / o a lo nuevo quijotil / Dulcinea de la Mancha? " (p. 846).

\section{La fingida Arcadia}

Incluso en una comedia de evidente homenaje a Lope, La fingida Arcadia, se encuentran guiños cervantinos a la locura de don Quijote, especialmente en la protagonista, Lucrecia, que finge que la lectura de la Arcadia lopesca la ha enloquecido para lograr el buen fin de sus amores. Pero hay otras referencias concretas a la novela en boca de su instruida criada, Ángela: la primera al comienzo de la comedia en respuesta a su ama Lucrecia que quiere convertir su estado en la Arcadia que Lope pinta, le dice:

$$
\begin{array}{ll}
\text { Ángela } & \text { Si en deseos semejantes } \\
\text { te desvaneces, señora, } \\
\text { notable falta hace agora } \\
\text { en nuestra España Cervantes, } \\
\text { que a su manchego hazañoso } \\
\text { loco por caballerías, } \\
\text { le prometió en breves días } \\
\text { hacer legítimo esposo } \\
\text { de otra dama, que, perdida } \\
\text { por quimeras pastoriles, } \\
\text { entre Dianas y Giles } \\
\text { rematase seso y vida (vv. 235-246). }
\end{array}
$$

Versos que aluden al episodio del capítulo 67 de la segunda parte del Quijote en que el caballero andante determina "hacerse pastor y seguir la vida del campo" con la 


\section{Blanca Oteiza}

intención de "renovar e imitar la pastoral Arcadia"; y otra, en la segunda jornada de nuevo en boca de Ángela ahora con alcance instructivo:

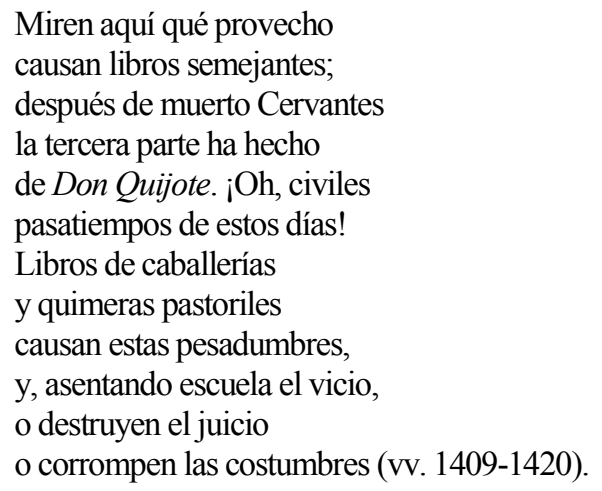

La Arcadia, como ente de ficción, es considerada nociva por todos estos personajes y causa, como los libros de caballerías en el Quijote, de la locura de Lucrecia, añadiendo además, como explica Roncero en su edición (23-24), la visión moralizante que veía en ambos géneros novelescos un peligro para la moralidad de los lectores.

\section{Marta la piadosa}

Un último caso interesante es el de Marta la piadosa, comedia de enredo urbana, receptora asimismo de otra referencia cervantina. Don Felipe y su criado Pastrana han llegado a Illescas; don Felipe huye de la justicia y se lamenta de su desgracia, mediante la descripción de un emblema, que Tirso llama "símbolo", diciendo a su criado:

$$
\begin{aligned}
& \text { Si mis desdichas recelas, } \\
& \text { sírvate en esta ocasión } \\
& \text { el símbolo del halcón } \\
& \text { con capirote y pigüelas, } \\
& \text { que alivia mi desventura } \\
& \text { el misterioso letrero } \\
& \text { donde dice: "Alegre espero } \\
& \text { tras las tinieblas luz pura". } \\
& \text { Ansí yo, si desterrado } \\
& \text { una muerte me hace andar, } \\
& \text { luz cual él puedo esperar } \\
& \text { después de tanto nublado. } \\
& \text { (vv. } 377-400 \text { ) }
\end{aligned}
$$

El sentido de 'las cosas mejorarán' es claro, pero no es un emblema inocente, por así decir, sino que encierra dos alusiones cervantinas: la de la conocida imagen de un halcón con capirote sobre una mano y un león dormido debajo, que tiene por lema el texto bíblico de Job $(16,12)$, Post tenebras spero lucem, que adoptó el impresor 
madrileño de obras cervantinas Juan de la Cuesta, responsable de las dos partes del Quijote, las Novelas ejemplares, y el Persiles ${ }^{13}$, y la de la analogía situacional de don Felipe y su criado con la del Quijote y Sancho, que se explicita poco después por Pastrana, el criado nuevamente:

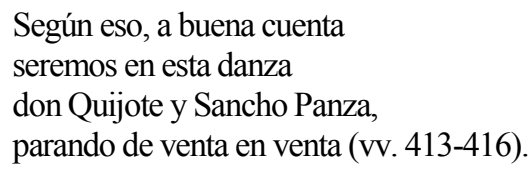

\section{Cigarrales de Toledo y deleitar aprovechando}

Otra perspectiva tienen las referencias cervantinas en su prosa, más próxima al Tirso que expone sus ideas sobre el teatro y la novela en su obra: en Cigarrales de Toledo, en sus comedias, especialmente El vergonzoso en palacio y La fingida Arcadia; en los paratextos de las tercera, cuarta y quinta partes de sus comedias, etcétera.

Y es en Cigarrales de Toledo, su primera miscelánea, de carácter profano, y redactada ya en 1621, donde tiene espacio el novelista Cervantes en dos ocasiones: la primera en la dedicatoria de Tirso "Al bien intencionado", cuando anuncia doce suyas: "También han de seguir mis buenas o malas fortunas, Doce Novelas, ni hurtadas a las toscanas, ni ensartadas unas tras otras como procesión de disciplinantes, sino con su argumento que lo comprehenda todo" (108), es decir, para distanciarse de las novelas cervantinas, porque sus novelas no seguirán el modelo de Boccaccio ni el de Cervantes, basado en una sucesión de novelas cortas sin vínculo y sin marco integrador ${ }^{14}$. Y en la segunda, para elogiarlo comparándolo con Boccaccio, por boca de Narcisa, responsable de organizar la actividad del segundo cigarral: un juego amoroso alegórico en el que los caballeros deben intentar superar pruebas de ingenio para llegar al Castillo de la pretensión de amor, que permite la analogía con la aventura amorosa de don Quijote y la ponderación de su autor, fallecido hacía pocos años: "Paréceme, señores, que después que murió nuestro español Bocacio, quiero decir, Miguel de Cervantes, ejecutor acérrimo de la expulsión de andantes aventuras, comienzan a atreverse caballerescos encantamientos" (236).

Y en la misma línea se referirá a Cervantes, y a otros más, en la segunda miscelánea, Deleitar aprovechando, de carácter religioso y doctrinal, redactada antes de 1632. La mención cervantina se inserta asimismo en un prólogo explicativo sobre el género de la novela hagiográfica y su modelo que presenta como nuevo ("novelar a lo santo", lo llama):

Si tanto se recrea el común gusto con lo peregrino de los cuentos, lo enmarañado de los amores, [...] lo ingenioso de las trazas y lo quimérico de las aventuras, ni en cuanto el Bocacio, el Giraldo, el Bandelo y otros escribieron en toscano,

\footnotetext{
${ }^{13}$ Ver más sobre este emblema en Quijote, vol. I, 2, y vol. 2, 251.

${ }^{14}$ Ver Dartai, 11.
} 
Heliodoro en griego, [...] los autores de los Belianises, Febos, Primaleones, Dianas, Guzmanes de Alfarache, Gerardos y Persiles en nuestro castellano, pueden compararse (puesto que todos son patrañas) con los sucesos portentosos, raros y verdaderos de estos tres sujetos (9),

o sea, los santos sobre los que va a novelar sus vidas. Así que Tirso conoce los modelos narrativos y los sigue pero no servilmente sino mejorándolos de manera novedosa con una disposición nueva ${ }^{15}$.

En suma, aun siendo temas recurrentes las relaciones entre ambos autores y la deuda de Tirso con la obra de Cervantes solo puede constatarse que el Mercedario la conoce y la reconoce evocándola en su teatro y en la prosa, donde sin embargo junto con el elogio al novelista Cervantes se distancia de él dejando en evidencia su propio ingenio con sus mejoradas y novedosas propuestas narrativas.

\section{GRISO-Universidad de Navarra* \\ Campus Universitario, s/n 31009 Pamplona (España) \\ boteiza@unav.es}

\section{OBRAS CITADAS}

Abrams, Fred. "Avellaneda and Tirso de Molina in Cervantes' Prologue to the Quijote". Romance Notes 11 (1969): 137-143.

_ "Tirso de Molina Alias Sancho Panza and a New Cervantine Etymology for Barataria". Romance Notes 9 (1968a): 281-286.

— "Pedro Noriz and Tirso de Molina in the Enchanted Head Episode of the Quixote". Romance Notes 10 (1968b): 122-128.

Asensio, Jaime. “¿Es Tirso ‘el otro’ de El viaje del Parnaso de Cervantes?”. Revista Canadiense de Estudios Hispánicos 10 (2) (1986): 154-172.

Close, Anthony. "Convergencia de comedia y novela en Tirso de Molina", en El mundo como teatro. Estudios sobre Calderón de la Barca. Ed. José Lara Garrido. Málaga: Analecta Malacitana-Universidad de Málaga, 2003:131-149.

Dartai-Maranzana, Nathalie. "La poética de Tirso y su evolución a la luz de sus dos misceláneas", en Prosas y versos de Tirso de Molina. Ed. Blanca Oteiza. Madrid-Pamplona: Instituto de Estudios Tirsianos, 2015: 25-42.

De Cervantes, Miguel. Don Quijote de La Mancha. Ed. Francisco Rico. Barcelona: CECE, Galaxia Gutenberg-Círculo de Lectores, 2004, 2 vols.

_ Viaje del Parnaso. Ed. Miguel Herrero García. Madrid: CSIC, 1983.

De los Ríos, Blanca. "De cómo un auto de Tirso se transmuta en novela de Cervantes". Revista Nacional de Educación 1,12 (1941): 35-64.

Díaz-Solís, Ramón. Avellaneda en su Quijote. Colombia: Tercer Mundo, 1978.

\footnotetext{
${ }^{15}$ Palomo apunta la significativa ausencia del Quijote, se pregunta si sería intencionada y qué tienen en común estos autores y títulos $(324,408)$.
} 
Fernández de Avellaneda, Alonso. Segundo tomo de El ingenioso hidalgo don Quijote de la Mancha. Eds. Milagros Rodríguez Cáceres y Felipe B. Pedraza. Ciudad Real: Diputación Provincial, 2014.

Florit, Francisco. "Una comedia de encargo: La vida de san Pedro Nolasco (1629) de Lope de Vega", en La comedia de santos. Eds. Felipe B. Pedraza y Almudena García. Almagro: Ediciones de la Universidad de Castilla-La Mancha, 2008: 201-217.

"Lope de Vega y Tirso de Molina en 1621: la dedicatoria de Lo fingido verdadero", en Otro Lope no ha de haber: Atti del convegno internazionale su Lope de Vega. Ed. Maria Grazia Profeti. Firenze: Alinea Editrice, 2000: III, 85-96.

Friedman, Edward. "Resonancias cervantinas en El vergonzoso en palacio", en Tirso en el siglo XXI. Ínsula 681 (2003): 17-20.

García López, Jorge. Cervantes. La figura en el tapiz. Itinerario personal y vivencia intelectual. Barcelona: Ediciones de Pasado y Presente, 2015.

García Martín, Manuel. "Dos modelos cervantinos en Tirso de Molina". Anales cervantinos 17 (1978): 137-146.

Jones, Cyril A. "Tirso de Molina's El melancólico and Cervantes' El licenciado Vidriera", en Studia Iberica: Festschrift fur Hans Flasche. Eds. Karl Korner y Klaus Ruhl. Bern: Francke, 1973: 295-305.

Jurado, Agapita. Obras teatrales derivadas de novelas cervantinas (siglo XVII). Kassel: Reichenberger, 2005.

Kennedy, Ruth L. "Estudios sobre Tirso. I. El dramaturgo y sus competidores (16201626)". Revista Estudios, 1983.

_ “Sobre la relación de Tirso con Cervantes". Boletín de la Real Academia Española 59 (1979): 225-288.

Madrigal, José Luis. “Tirso, Lope y el Quijote de Avellaneda”. Lemir 13 (2009): 191-250.

Navarro, Rosa. "Don Gil de las calzas verdes a la luz de Cervantes", en La comedia de capa y espada. Eds. Felipe B. Pedraza, Rafael González Cañal y Elena Marcello. Almagro: Ediciones de la Universidad de Castilla-La Mancha, 2004: 17-37.

Osuna, Rafael. "Cervantes y Tirso de Molina: se aclara un enigma del Persiles". Hispanic Review 42. 1974: 359-368.

Palomo, Pilar. Estudios tirsistas. Málaga: Universidad, 1999.

Sliwa, Krzysztof. Cartas, documentos y escrituras del Dr. Frey Lope Félix de Vega Carpio (1562-1635). Newark. Delaware: Juan de la Cuesta, 2007, 2 vols.

Suárez, Ana. "Complejidad de motivos en El celoso prudente", en Prosas y versos de Tirso de Molina. Ed. Blanca Oteiza. Madrid-Pamplona: Instituto de Estudios Tirsianos, 2015: 215-229.

Tirso de Molina. La fingida Arcadia. Ed. Victoriano Roncero. Madrid-Pamplona: Instituto de Estudios Tirsianos, 2016.

_ Cómo han de ser los amigos. El amor y el amistad. Ed. María Teresa Otal, Madrid-Pamplona: Instituto de Estudios Tirsianos, 2007. 
__ La villana de la Sagra. Ed. Alfredo Hermenegildo. Madrid-Pamplona:Instituto de Estudios Tirsianos, 2005.

_ El castigo del penseque, en Tirso de Molina. Doce comedias nuevas. Ed. Pilar Palomo. Madrid:Turner (Biblioteca Castro), 2004.

— Mari Hernández, la gallega. Ed. Sofía Eiroa, Madrid-Pamplona:Instituto de Estudios Tirsianos, 2003.

— No le arriendo la ganancia, en Obras completas. Autos sacramentales I. Eds. Ignacio Arellano, Blanca Oteiza y Miguel Zugasti. Madrid-Pamplona: Instituto de Estudios Tirsianos, 1998.

— Cigarrales de Toledo. Ed. Luis Vázquez, Madrid:Castalia, 1996.

— Deleitar aprovechando. Ed. Pilar Palomo, Madrid: Turner-Biblioteca Castro, 1994.

— Amar por señas, en Obras dramáticas completas. Ed. Blanca de los Ríos, Madrid:Aguilar, 1989: vol. II.

_ Don Gil de las calzas verdes. Marta la piadosa. Ed. Ignacio Arellano, Barcelona: PPU, 1988.

_ Tanto es lo de más como lo de menos, en Obras dramáticas completas. Ed. Blanca de los Ríos, Madrid: Aguilar, 1946: vol. I.

Vaiopoulos, Katerina. De la novela a la comedia: las "Novelas ejemplares" de Cervantes en el teatro del Siglo de Oro. Vigo: Academia Editorial del Hispanismo, 2010.

_ “La versión teatral de La señora Cornelia de Cervantes". Hesperia. Anuario de filología hispánica 12-1 (2009): 105-125.

Vázquez, Luis. "Tirso de Molina, probable autor del Quijote de Avellaneda", en $V$ Actas de la Asociación Internacional Siglo de Oro (1999), Madrid: Iberoamericana, 2001: 1296-1305.

__ “Tabula vitae", en Cigarrales de Toledo. Madrid: Castalia, 1996: 9-47. 